\title{
Scenario of HIV in Indian Rural Population: Editorial
}

\author{
Sabde Y \\ Dr Yogesh Sabde, Professor, Community Medicine, R D Gardi Medical College, Ujjain, India. Member, Editorial board, \\ IJMRR
}

Address for correspondence: Dr Yogesh Sabde, Email: sabdeyogesh@gmail.com

\begin{abstract}
HIV is spreading like epidemic all over world. Scenario is worse in developing countries like India. Rural India is facing more severe problem because of less awareness and accessibility to medical care.
\end{abstract}

\section{Burden of HIV in rural women of India:} Globally the number of people living with HIV / AIDS (PLHA) was estimated to be 34 million claiming 1.7 lives million in $2011^{1}$. In 2009 the estimated number of PLHA was 2.4 million (1.93-3.04 million) in India of which women comprises $39 \%{ }^{2}$. The current trends in India reveal that disease is spreading from urban areas to rural areas beyond groups with typically "highrisk" behaviour such as sex workers, STI clinic attendees and long-distance truck drivers ${ }^{2-4}$. The spread of HIV in rural areas is favoured by widely prevalent sexually transmitted infections (STIs). Rural women are at the highest risk of STIs and likely becoming easy prey for HIV/AIDS too ${ }^{5}$. Apart from the known risk factor of being married to men who transmitted the disease to them via sexual activity; HIV-positive women were significantly more likely to report marital dissatisfaction, a history of forced sex, domestic violence, depressive symptoms and husband's extra marital sex when compared to the HIV-negative women ${ }^{6}$. Women are also at higher risk of psychiatric comorbidities among which most common is depression ${ }^{7}$. In rural Punjab, the data suggests that approximately $66 \%$ of women had depression compared to $25 \%$ of men $^{8}$. In addition, HIV-positive women were more likely than HIV-positive men to take care of their partners and neglect their own health ${ }^{9,10}$.
Challenges in control: HIV/AIDS prevention and care face unique challenges in rural settings of India viz. poor education, limited access to health care and social services, and isolation due to social stigma and a lack of infrastructure and public transportation ${ }^{11}$. The HIV positive rural women also have to face an all pervasive stigma and reluctant discrimination at all levels including health care service facilities ${ }^{12}$. Traditional values and stigma also account for some obstacles that keep rural women from talking about sexuality and learning how to prevent HIV/AIDS. Fear of stigma also stops these women from getting tested, learning their results, and disclosing their HIV status. Women are less likely than men to seek testing, and less able than men to afford treatment ${ }^{13}$. All such factors had limited the success rates of known interventions like group counselling to improve HIV / AIDS awareness among rural women in spite of increasing risk of infection ${ }^{14}$. Therefore though the awareness about HIV/AIDS disease has increased among general population, the people in rural areas and particularly the women are not so much aware about the modes of transmission and prevention of the disease.

Equity recommendations in policy: In 2011, WHO Member States adopted a new Global health sector 


\section{Editorial}

strategy on HIV/AIDS for 2011-2015 ${ }^{15}$. The common theme for world AIDS days between 2011 to 2015 is "Getting to zero: zero new HIV infections. Zero discrimination. Zero AIDS related deaths". The zero discrimination means that all the population subgroups have equitable access to the care that helps in prevention and treatment of the disease ${ }^{16}$. In India urgent interventions to address gender sensitivity and HIV-related communication and clinical skills particularly in rural areas are recommended ${ }^{17}$. On this background it is essential to conduct more research on the various aspects of HIV epidemic in rural women.

The article presented by Gayathri $\mathrm{V}^{18}$ et al in this issue reports the HIV disease course among rural women receiving ART. This was a retrospective study with primary aim to explore the course of HIV and response to ART in terms of improvement of $\mathrm{CD}_{4}$ counts among rural women. The study reports that ART succeeded in improving the $\mathrm{CD}_{4}$ counts of $80 \%$ women and the response was better in younger age groups. The study identified low $\mathrm{CD}_{4}$ counts and tuberculosis as frequently associated factors among women who died during the course of treatment. The study in has succeeded in documenting the determinants of deaths in these cases. However it does not provide sufficient primary evidence prove that the disease course adverse among rural women as compared to their counterpart's viz. men and urban residents as there was no comparison among the groups.

\section{References}

1. World AIDS Day Report 2011. Available at: http://www. unaids.org/ en/media/unaids/contentassets/documents/unaidspublicati on/2011/jc2216_worldaidsday_report_2011_en.pdf

Accessed October 10th, 2013.

2. Pandey A, Sahu D, Bakkali T, Reddy D, Venkatesh S, Kant S, Bhattacharya M, Raj Y, Haldar P, Bhardwaj D, Chandra N. Estimate of HIV prevalence and number of people living with HIV in India 2008-2009. BMJ
Open. 2012 Sep 30;2(5). pii: e000926. doi: 10.1136/bmjopen-2012-000926. Print 2012

3. Pallikadavath S, Garda L, Apte H, Freedman J, Stones RW. HIV/AIDS in rural India: Context and health care needs. Journal of Biosocial Science. 2005;37:641-655.

4. Becker ML, Ramesh BM, Washington RG, Halli S, Blachard JF, Moses S. Prevalence and determinants of HIV infection in South India A heterogenous rural epidemic. AIDS. 2007 Mar 30;21(6):739-47.

5. NIMH Collaborative HIV/STD Prevention Trial Group.Sexually transmitted disease and HIV prevalence and risk factors in concentrated and generalized HIV epidemic settings. AIDS. 2007 Apr;21 Supp1 2:S81-90.

6. Gupta RN, Wyatt GE, Swaminathan S, Rewari BB, Locke TF, Ranganath V, Sumner LA, Liu H. Correlates of relationship, psychological, and sexual behavioral factors for HIV risk among Indian women. Cultur Divers Ethnic Minor Psychol. 2008 Jul;14(3):25665. doi: 10.1037/1099-9809.14.3.256

7. Chandra PS, Desai G, Ranjan S. HIV \& psychiatric disorders. Indian Journal of Medical Research. 2005;121:451-67.

8. Mumford DB, Saeed K, Ahmad I, Latif S, Mubbashar MH. Stress and psychiatric disorder in rural Punjab. A community survey. British Journal of Psychiatry. 1997; 170:473-478.

9. Bharat S, Aggleton P, Tyrer P. India: HIV and AIDSrelated Discrimination, Stigma and Denial. Geneva: UNAIDS Best Practice Collection. 2001

10. O’Neil J, Orchard T, Swarankar RC, Blanchard JF, Gurav K, Moses S. Dhandha, dharma and disease: traditional sex work and HIV/AIDS in rural India. Social Science \& Medicine. 2004;59:851-860. 


\section{Editorial}

11. Saini NK, Sharma R, Roy R, Verma R. What impedes 14. Gupta D, Lhewa D, Viswanath R, Jacob working in rural areas? A study of aspiring doctors in the National Capital Region, India. Rural Remote Health. 2012;12:1967: 1-7.

12. Nyamathi AM, William RR, Ganguly KK, Sinha S, Heravian A, Albarrán CR, Thomas A, Greengold B, Ekstrand M, Ramakrishna P, Rao PR. Perceptions of Women Living with AIDS in Rural India Related to the Engagement of HIV-Trained Accredited Social Health Activists for Care and Support. J HIV AIDS Soc Serv. 2010 October; 9(4): 385-404

13. Nyamathi AM, Sinha S, Ganguly KK, William RR, Heravian A, Ramakrishnan P, Greengold B, Ekstrand M, Rao PV. Challenges experienced by rural women in India living with AIDS and implications for the delivery of HIV/AIDS care. Health care for women international. 2011Apr;32(4):300-13. doi: 10.1080/07399332.2010.536282.

SM, Parameshwari S, Radhakrishnan R, Seidel K, Frenkel LM, Samuel NM, Melvin AJ. Effectiveness of antenatal group HIV voluntary counseling and testing services in rural India. AIDS Educ Prev. 2007 Jun;19(3):187-97

15. Global Health Observatory (GHO) HIV/AIDS. Available at: http://www.who.int/gho/hiv/en/ Accessed October 23rd, 2013

16. WHO campaigns. World AIDS Day, 1 December 2013 Available at: http:/www.who.int/campaigns/aidsday/2013/en/index.html Accessed October 23rd, 2013

17. Sinha G, Peters DH, Bollinger RC. Strategies for gender-equitable HIV services in rural India. Health Policy Plan. 2009 May;24(3):197-208. doi: 10.1093/heapol/czp004. Epub 2009 Feb 25

18. Gayathri V, Ramanamma VM. A Study of HIV Disease Course Among Rural Women Receiving ART. Int J Med Res Rev 2013;1(4):184-189

\section{How to cite this article?}

Sabde Y. Scenario of HIV in Indian Rural Population: Editorial. Int J Med Res Rev 2013;1(4):146-148. doi:10.17511/ijmrr.2013.i04.01 